\title{
The Importance of Evidence: The Legacy of Archie Cochrane
}

The establishment of Cochrane Russia within the Kazan Federal University is a great triumph. Even more significant, perhaps, it is indication of the determination of the medical leadership in Tatarstan to contribute to the scientific factual basis for judgments and interventions in the practice of medicine. The faculty of the university is to be congratulated for showing its interest in the quality of the evidence in medicine and, as a result, for having been selected to serve as the Russian Branch of the Nordic Cochrane Centre.

Archie Cochrane was a complex individual - as are essentially all who eventually make substantial contributions to humanity. He early chose a path toward psychiatry and psychoanalysis in Vienna in the shadow of Sigmund Freud. As he noted much later, he “...couldn't test its hypotheses.”

Archie Cochrane turned toward socialism as he was deeply impressed by the aspect of unemployment in the 1930's. He joined the International Brigade in the Spanish Civil War and took part in at least five major battles. He returned to London and qualified as a doctor at University College Hospital and settled into research only to face a new challenge, the outbreak of World War II. On active duty, he was shortly taken prisoner where he remained for the next four years. In this setting, he served as the physician for thousands of prisoner patients suffering from tuberculosis and diphtheria and a variety of other disorders. It was this experience that led him to epidemiology and to an intellectual curiosity about what does and does not work in medicine. He wondered why certain of the patients survived. He concluded that it had little to do with therapy in contrast to the recuperative processes of the human organism.

With very few therapeutic or even analgesic agents to use, he was drawn to observations as to what was effective and what was not. In later years, during a lecture in Germany, he thanked the audience for leading him into the productive fields of epidemiology and thinking about the health of the community.

Between 1951 and 1968, he watched the birth of the National Health Service and a substantial increase in the number of medical resources in the UK. Requests for pathology tests increased threefold and the number of $x$-ray units doubled. This propelled him to question the usefulness or perhaps wastefulness of some of what medicine did. He focused in this on type II diabetes, hypertension and the very active practice of tonsillectomy in children. It was this experience that spawned his most famous book, Effectiveness and Efficiency in the National Health Service. He eventually returned to his home territory in Wales and to the epidemiological study of pneumoconiosis among Welsh coal miners.

In all of this, he believed that much of medicine did not have sufficient evidence to justify its use. This, of course, was a serious challenge to practitioners and to their institutions. Cochrane expressed an unwavering position that controlled clinical trials were a requisite for judging effectiveness.

Archie Cochrane was always humorous, self-effacing and self-deprecating. Cochrane liked to think of himself as a heretic. At one point late in his career, he was heard to say, "I am getting rather old and we don't seem to be producing any young heretics."

I briefly knew Archie Cochrane and can attest to his ingenuous and generous personality. During one of his visits to the United States in the 1970's, I had the pleasure of bringing him and his points of view to the attention of the leadership of the National Institutes of Health in Washington. 
His legacy, rigorous attention to the evidentiary basis of medicine, is now established. The Cochrane Library and the Cochrane collaboration represent the data bases for medicine. The vision of the Cochrane Collaboration is stated as a "...world of improved health where decisions about health and health care are informed by high quality, relevant and up-to-date synthesized research evidence.”

Edward J. Burger, M.D., Sc.D. December 2015 